OpInIÓN 



\title{
El conflicto US-China: nueva fase de la globalización
}

\author{
Por Osvaldo Rosales*
}

\section{INTRODUCCIÓN}

Casi al finalizar la segunda década del siglo XxI, enfrentamos una gran paradoja que prácticamente cierra un ciclo en la economía mundial. En efecto, a inicios de los '80s, Reagan en Estados Unidos (EE.Uu.) y Thatcher en el Reino Unido, construían los cimientos del neoconservadurismo, otorgando un gran impulso a la globalización, desregulando mercados, abriendo las economías, derrumbando los "socialismos reales" y promoviendo el "ajuste estructural" en los organismos internacionales. Cuarenta años después, son justamente los Estados Unidos con Trump y el Reino Unido con el Brexit, los que ponen un freno en la tendencia globalizante y recurren a medidas proteccionistas en el primer caso y a un debilitamiento de la principal experiencia integracionista - la UE—, en el segundo.

\footnotetext{
Ex Vice-Ministro de Comercio de Chile, 2000-2004, y ex Director de Comercio Internacional e Integración, CEPAL, Naciones Unidas, 2005-2015.
}

En el caso de Trump, su administración impulsó la salida del Acuerdo de París, la salida del TPP, la renegociación del nafta y del korus, y ahora boicotea la nominación de árbitros en la омc e instaura una batería de restricciones a importaciones de bienes $\mathrm{y}$, eventualmente, también a inversiones.

El mensaje electoral de Trump ha capturado bien el descontento de sectores medios norteamericanos con los efectos de la actual modalidad de la globalización; sectores que han visto deteriorarse su calidad de vida por la concentración del ingreso, estancamiento salarial, pérdida de empleos manufactureros, viéndose presionados a enrolarse en servicios de baja remuneración. Para ello, ha construido un discurso donde culpa al comercio y particularmente al comercio con China de dichos males, apelando al ciudadano blanco y de baja educación de esas capas medias y medias bajas.

La crisis subprime de 2008-2009 en EE.Uu. marcó un punto de quiebre en la economía global. Clausuró un ciclo largo de crecimiento, 2003-2008, el 
mejor período de la economía mundial en 40 años. Las consecuencias de la subprime han sido reducir drásticamente el ritmo de crecimiento en las economías industrializadas, caída en la tasa de inversión y en el dinamismo del comercio internacional. La postcrisis golpeó con singular intensidad a Europa, de modo que las "políticas de austeridad" para enfrentar la crisis agravaron el descontento social. Ante la debilidad de las opciones socialdemócratas en la UE, la crisis y la postcrisis han coincidido con fortalecimiento de los nacionalismos y populismos de ultraderecha en la UE, debilitando las perspectivas del proceso de integración europeo. En paralelo, China ha continuado aportando dinamismo a la economía mundial, junto con conseguir importantes avances en materia de innovación y nuevas tecnologías.

Este "renacer chino" ha generado inquietudes en EE.uU. y en Europa, toda vez que China va cerrando las brechas tecnológicas con las economías industrializadas de Occidente. Es aquí cuando surge la estrategia de Trump: "United States first", enfocada básicamente a frenar el avance tecnológico chino. Por eso es importante no perder de vista que la "guerra comercial" no es más que una fase inicial de un conflicto de mayor duración. Lo que realmente está en juego es la hegemonía tecnológica en el resto del siglo xxi. Entramos a una nueva fase de la globalización, marcada por esta pugna tecno-económica entre EE.UU. y China por el control de las tecnologías del siglo xxi: IA, Iot, Big Data, robotización, etc., todos ámbitos en los que China viene desplegando importantes esfuerzos.

\section{Una visión de largo plazo}

Para entender el contexto de esta disputa es importante comprender la visión de largo plazo que define las políticas chinas. Los objetivos del actual "sueño chino" fueron definidos por el xviri Congreso Nacional del Partido, en relación a dos importantes centenarios: el de la fundación del Partido en 2021 y el de la Nueva China en 2049. De este modo, las metas serían "para 2020 duplicar el PIB y el ingreso per cápita rural y urbano respecto de 20Io, cumpliendo así con la construcción de una sociedad modestamente acomodada $^{1} \mathrm{y}$, para mediados de siglo, concluir la transformación de China en un país socialista moderno, próspero, poderoso, democrático, civilizado y armonioso, haciendo así realidad el sueño chino de la gran revitalización de la nación china" (Xi, 20I4: 70).

De este modo, al cumplir el "sueño chino" se estaría viviendo el "retorno a la normalidad histórica”, es decir, al

1 La "modernización a lograr en 2020 " se resume en conseguir "un desarrollo sostenible y saludable de la economía; duplicar el ingreso por habitante rural y urbano respecto de 20I0; ampliación de la democracia popular; fortalecimiento de la cultura; elevación del nivel de vida del pueblo; importantes avances en construir una sociedad ecológica y ahorradora de recursos" (Xi, 20I4:22, nota 2) 
momento en que el Reino del Medio ocupaba un lugar central en la economía mundial. Este largo período habría sido interrumpido por el "siglo de la humillación”, iniciado con la Guerra del Opio en I84I y solo concluido en 1949 con la gestación de la República Popular China. Un siglo más, desde 1949 a 2050, estaría demorando entonces este "retorno a la normalidad histórica", con China en el epicentro de la economía mundial (ver Diagrama I)

Esta mirada larga ayuda a entender los límites y posibilidades del accionar chino en su debate con Ee.uU. Puede haber flexibilidad y búsqueda de acuerdos, pero difícilmente se abandonarán los pilares de este sueño. En mi opinión, la estación final de 2050 tiene una estación intermedia en 2025 , con la iniciativa Made in China 2025.

La propuesta "Made in China 2025" surgió en octubre de 2015 y busca fortalecer la innovación y el desarrollo de las nuevas tecnologías, focalizándose en tres objetivos: i) que la industria manufacturera consiga ascender en la jerarquía tecnológica de las cadenas de valor; ii) transformar a China en potencia tecnológica, y iii) reestructurar el sector industrial, elevando su eficiencia, calidad y capacidad de innovación.

El programa contempla tres fases: i) en 2025 , reducir la diferencia tecnológica con los países líderes; ii) en 2035, fortalecer la posición tecnológica de China, y iii) en 2045, liderar la innovación global.
Los principales instrumentos que se privilegiarán serán: i) reestructurar la industria manufacturera, mejorando en eficiencia, calidad, estándares, automatización y uso y creación de nuevas tecnologías; ii) promover la innovación, la propiedad intelectual y el desarrollo sostenible, y iii) facilitar la fusión y reorganización de empresas.

Esta propuesta busca enfrentar la desaceleración en la productividad y en la tasa de crecimiento económico, en la caída en la tasa de expansión de la fuerza de trabajo - dado el efecto de la política de "un solo hijo" en la transición demográfica-y el incremento en el costo de la mano de obra vis a vis la competencia de otras economías asiáticas de menores ingresos, como Vietnam e Indonesia.

En palabras del Primer Ministro Li Keqiang, "el crecimiento debe converger de una era de velocidad a una era de calidad". Para ello se busca reforzar el vínculo entre industrialización e informatización, incorporando masivamente a la gestión industrial la robótica, Internet de las Cosas, Big Data; e-cloud y la Inteligencia Artificial.

El plan "Made in China 2025" apuesta a Io sectores:

- Nuevas tecnologías avanzadas de información.

- Robótica y máquinas automatizadas.

- Aeroespacio y equipamiento aeronáutico.

- Equipamiento marítimo y barcos de tecnología avanzada.

- Moderno equipamiento ferroviario. 


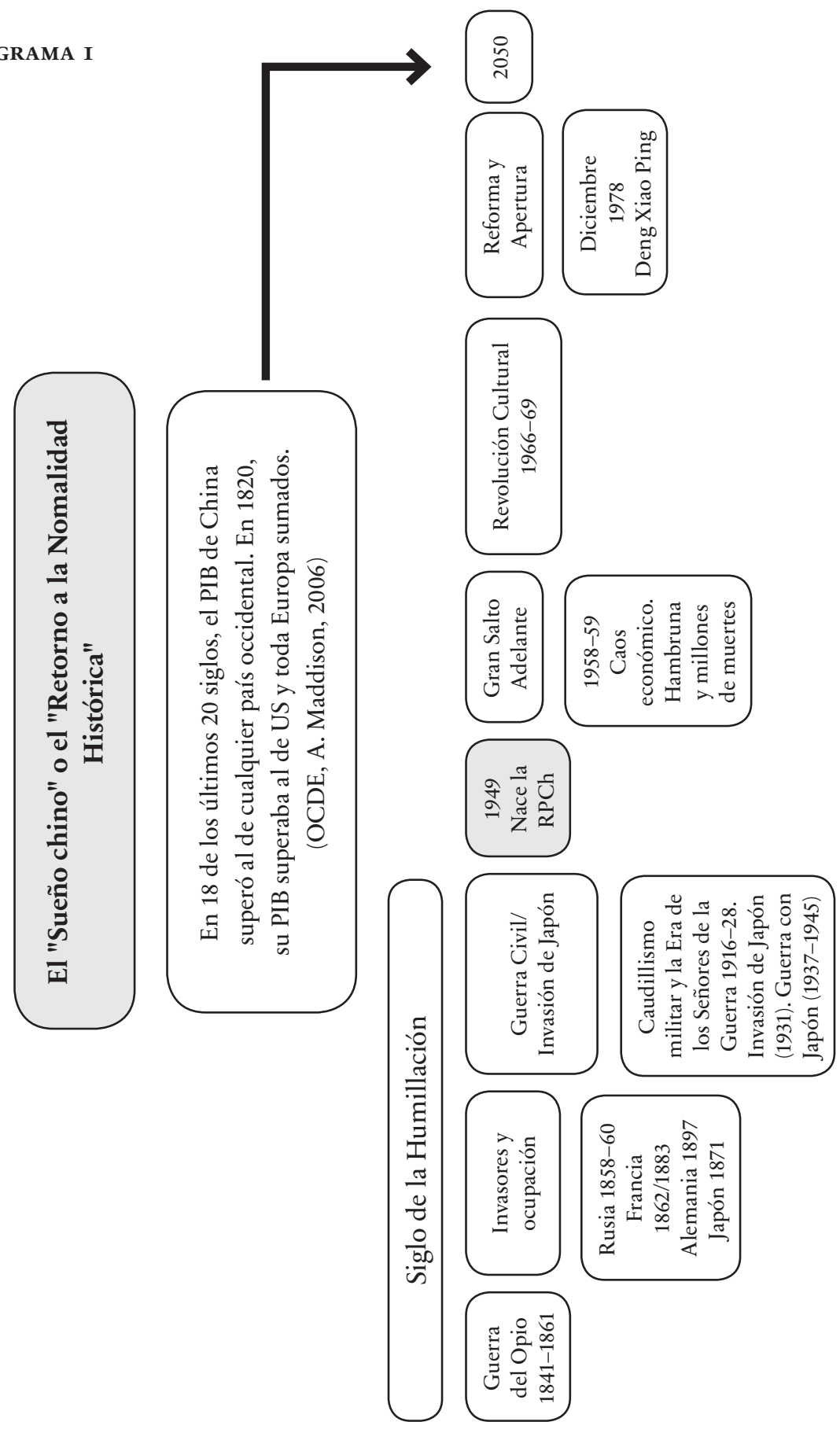


- Vehículos con nuevas energías y su equipamiento.

- Equipos de energía; eficiencia energética.

- Equipos agrícolas.

- Nuevos materiales.

- Biofarma y productos médicos avanzados.

En cada uno de estos Io sectores, se trabajará en 5 áreas:

- Formar Centros de Innovación.

- Promover la Fabricación Inteligente.

- Fortalecer la infraestructura industrial compatible con las nuevas tecnologías.

- Generar empresas de fabricación sustentable.

- Producir equipos de alta gama.
Así, por ejemplo, se aspira a crear 15 nuevos Centros Nacionales de Ciencia y Hub de Innovación Tecnológica para 2020 y contar ya con 40 de ellos en 2025. Por cierto, esto supone un gasto considerable. Al respecto, la ocDE estima que, medido en dólares, ya en 2019 China será el país con mayor inversión en I\&D, superando a Estados Unidos ${ }^{2}$. En el 2020, China estaría asignando un $2,5 \%$ del pIB al gasto en I\&D. ${ }^{3}$

Este es el contexto en el que se desenvuelve la denominada "guerra comercial" entre Ee.uU. y China. No es, entonces, una diferencia estrictamente comercial, si bien la incluye, pero va mucho más allá y será bastante duradera.

\section{LOS TEMAS EN DISCORDIA EN LA PUGNA COMERCIAL EE.UU.-CHINA:}

Es bueno conocer la agenda de la discordia entre EE.uU. y China, de modo de calibrar la posibilidad de eventuales logros de una u otra parte en plazos cortos. ${ }^{3}$

2 OCDE, Science, Technology and Industry Outlook 20I4. En 20I2, el gasto en I\&D en Estados Unidos fue de US\$ 397 mil millones; en la UEde US\$282 mil millones y en China de US\$257 mil millones.

3 Ver knowledge.ckgsb.edu.cn/2015/09/02/ technology/made-in-china-2025-a-new-erafor-chinese-manufacturing

\section{A. Los alegatos de Estados Unidos:}

i.- El saldo comercial: El factor más evidente en la agenda norteamericana es la magnitud de su déficit comercial y la alta presencia china en el mismo. La visión mercantilista de Trump y su equipo interpreta el poder económico como sinónimo de superávit comercial, despreciando la teoría económica que indica que el desequilibrio comercial corresponde a un desequilibrio macroeconómico, esto es, a la diferencia entre ahorro e inversión.

En lo estrictamente comercial, esta política es una reminiscencia de los mercaderes del siglo xvi y xviı, quienes 
se enriquecían con el exceso de sus ventas por sobre sus compras, saldo que acumulaban en oro y plata. Adam Smith cuestionó la proyección de esta situación individual a la de los países, proyección que llevaba a privilegiar las exportaciones y penalizar las importaciones. Fue Smith quien justamente la denominó "mercantilismo".

Con este criterio mercantilista, el comercio es visto como un ejercicio de suma-cero, es decir, donde lo que un país gana, lo pierde otro. No cabe en este enfoque la posibilidad del beneficio mutuo, ni las ventajas de la especialización ni la lógica de la ventaja comparativa. En el límite, este argumento mercantilista enlaza bien con un intervencionismo que favorezca a las empresas domésticas en comercio e inversión, apelando a aranceles, subsidios, ventajas tributarias y administrativas. Esto es exactamente lo que pretende hacer Trump. Como EE.UU. enfrenta déficits comerciales con 102 países, el desafío es arduo y habla de la necesidad de considerar esta política con seriedad, pues de continuar, significaría destruir todo el edificio multilateral construido a partir del GATT y luego con la омс.

\section{ii.- Sobre-oferta y subsidios chi-} nos en sectores claves: Un conjunto de antecedentes asociados a las características del modelo chino de crecimiento ${ }^{4}$ ha conducido a una sosteni-

4 Rápidamente se pueden indicar los siguientes: exceso de inversión, economías de escala, subsidios varios (tasa de interés, da y amplia sobre-oferta en sectores manufactureros claves, tales como acero, aluminio, cemento y vidrio, entre otros. Esto ha sido recogido en el alegato norteamericano. A continuación, un par de párrafos de la presentación del representante de Estados Unidos en la omc en julio 20I8, emitida bajo el título de "China's Trade-Disruptive Economic Model"

"China today is the world leader in excess capacity. For example, China's large increases in steel capacity since it joined the што in $200 \mathrm{r}$ have led to similarly large increases in steel production. China's annual steel production rose from 152 million MT in 2001 to 808 million MT in 2016, by far the largest in the world, and China's steel industry now accounts for 50 per cent of global steel production. China's steel exports have also grown to be the largest in the world, at 108 million MT in 2016, compared to 66 million MT a decade earlier".

"For example, China's excess capacity in solar panels was a key reason why US imports of solar cells and modules from China increased by 500 per cent from 2012 to 2016, while prices for solar cells and

terrenos), bajo costo de la mano de obra y pérdidas de las empresas asumidas por el Estado. Un factor adicional es que, durante décadas, el ascenso de los oficiales en el Partido ha estado ligado a logros en el incremento del pib en cada una de las regiones o provincias a su cargo, con independencia de la eficiencia de la inversión resultante, incluidos excesos de capacidad. Este es justamente uno de los temas que las reformas económicas en curso en China desean superar. 
modules fell by 60 per cent, to a point where most US producers ceased domestic production, moved their facilities to other countries, or declared bankruptcy. By 2017 , the US solar manufacturing industry had almost disappeared, with 25 companies closing since 20I2" (wTO, 20I8, p. 7).

El desafío, por tanto, es buscar la mejor estrategia para lidiar con este tema. Esta no es una materia que desconozcan las autoridades chinas. Al contrario, es una en la cual dicen estar trabajando y donde muestran algunos logros. Así se lee, por ejemplo, en un documento oficial: "In 2006, the State Council listed ten industries with overproduction challenges. In August 2009, the Financial Committee under the National People's Congress pointed out that the number of overproduction industries doubled and reached 19. Of them, such six industries as steel, aluminum, cement, ethylene, oil refining and wind power had the most obvious and serious problems" (Chi Fulin, 20I0, p. 25).

El avance en el desmonte de la capacidad excedente que puede significar fusiones y/o cierre de empresas no es fácil, pues ello puede significar lanzar miles de trabajadores a la calle, sin una alternativa ocupacional a la vista. De allí que uno de los principales obstáculos en estas reformas sea la resistencia de los administradores de esas empresas estatales, por un lado, y la de las autoridades locales o provinciales que deben dar la cara ante su comunidad producto del desempleo resultante, por otra. iii.- Baja observancia de los derechos de propiedad intelectual: El argumento norteamericano es que sus empresas en China estarían obligadas a establecer joint-ventures (JV) con empresas locales, presionadas a compartir sus innovaciones y su know-how tecnológico. De este modo, las empresas chinas se apropiarían indebidamente de los méritos tecnológicos de las empresas norteamericanas, sin cancelar los respectivos derechos de propiedad intelectual.

En este tema, el alegato norteamericano tiende a ser acompañado por similares inquietudes de sus pares europeos. Así, por ejemplo, la cámara de comercio europea con sede en Beijing alegaba -en un documento reciente- que la legislación china, si bien mostraba avances importantes, aún dejaba ver debilidades en patentes (proveer un período de gracia para la aplicación de diseños, clarificar las reglas para la entrega de datos experimentales); litigaciones civiles (revisar los estándares para la concesión de medidas cautelares); marcas comerciales (agilizar procedimientos de reconocimiento); derechos de autor (actualizar la legislación para penalizar la violación de estos derechos digitales), propiedad intelectual online (reforzar su protección) y secretos comerciales (facilitar el uso de medidas cautelares) (European Chamber of Commerce, 20I7).

La acusación norteamericana es más drástica, ya que habla de transferencia tecnológica forzada: “...the 
Chinese government uses foreign ownership restrictions, such as formal and informal JV requirements, to require or pressure technology transfer from US companies to Chinese entities... the Chinese government directs and unfairly facilitates the systematic investment in, and acquisition of, US companies and assets by Chinese entities, to obtain cutting-edge technologies and intellectual property and generate large-scale technology transfer in industries deemed important by state industrial plans... the Chinese government has conducted or supported cyber intrusions into US commercial networks targeting confidential business information held by US firms. China's unfair acts, policies and practices injure not only the United States, but also the rest of the Wто membership" (WTO, 20I8, p.7).

El alegato chino, a su vez, reconoce falencias en algunos de estos planos, pero replica explicitando importantes avances en cada una de estas áreas y justificando las debilidades por razones estructurales, como por ejemplo, el bajo número de abogados y jueces especialistas en temáticas de propiedad intelectual, así como temas culturales de larga data.

“The PRC's current inability to enforce its intellectual property laws is largely the result of I) the lack of a tradition respecting the sanctity of intellectual property rights; 2) provincial, local, and military involvement in counterfeiting, and resistance to the enforcement of national laws, and 3) the lack of viable and impartial judicial and administrative systems for dealing with intellectual property disputes" (Wilard, 1996).

iv.- Compras públicas: El alegato norteamericano señala las dificultades de sus empresas para acceder a las compras públicas del gobierno central y de los gobiernos regionales y locales de China. En cualquier caso, en este tema, el alegato chino reproduce textualmente los argumentos norteamericanos, pues ellos encuentran similares restricciones para acceder al mercado de compras públicas del gobierno central y de los estados de Ee.uU. Considerando la mayor relevancia del sector estatal en la economía china, es claro que el alegato norteamericano apunta a un objetivo económico de billones de dólares.

Aquí las principales falencias del sistema chino se pueden resumir en el sistema de gestión; la institucionalidad legal; la supervisión del sistema, particularmente la financiera; la estandarización de los procedimientos de compras públicas, y la formación de recursos humanos especializados en el tema (Guo Keguang, 2009).

\section{v.- Apertura en sector financiero:} Uno de los objetivos de las reformas económicas chinas es avanzar en la liberalización del sector financiero y la cuenta de capitales de la balanza de pagos. Sin embargo, ello no puede considerarse como una reforma de aplicación instantánea y de una vez. Menos aún considerando el amplio debate sobre las implicaciones de la apertura financiera y de la cuenta de capitales, tema donde incluso el FMI, 
otrora partidario de acelerar dicha apertura, hoy ha empezado a mostrar mayor cautela en este tema.

"The mounting evidence on the high cost-to-benefit ratio of capital account openness, particularly with respect to short-term flows, led the IMF's former First Deputy Managing Director, Stanley Fischer, now the vice chair of the U.S. Federal Reserve Board, to exclaim recently: "What useful purpose is served by shortterm international capital flows?" Among policymakers today, there is increased acceptance of controls to limit short-term debt flows that are viewed as likely to lead to-or compound - a financial crisis. While not the only tool availableexchange rate and financial policies can also help-capital controls are a viable, and sometimes the only, option when the source of an unsustainable credit boom is direct borrowing from abroad" (Ostry and others, 20I2).

Estados Unidos lleva varios años presionando para que China acelere esta apertura. La reacción china ha sido ratificar que esta apertura está en su agenda, pero que la modalidad precisa y los ritmos se van definiendo de manera gradual. Las autoridades chinas, entonces, están demandando que se respeten sus tiempos en esta reforma y ahora, considerando las restricciones que la inversión china empieza a enfrentar en EE.Uu. y en la UE están ligando la evolución de esta reforma a la reciprocidad, esto es, a la apertura a las inversiones chinas que muestren esos mercados.
Chen Wenhui, el vice-presidente de China Banking and Insurance Regulatory Commission (CBIRC) acaba de expresar que "Our country's opening must be based on the principle of equality and mutual benefit. It will not be carried out on a 'one-size-fits-all' basis, andshould stress mutual benefit and reciprocity"(CNBC, 20I8).

Los elevados niveles de deuda en la economía china, la persistencia del boom inmobiliario y los gigantescos montos de capitales envueltos hacen que las autoridades chinas sean particularmente cautelosas en el tema de la apertura financiera y de la cuenta de capitales. Baste recordar la violenta crisis en la Bolsa de Shanghai en agosto de 2015 , cuando esta sufrió una caída del $40 \%$ en pocas semanas, tras haber crecido $154 \%$ en doce meses.

Dicha crisis partió por la implementación de un nuevo sistema de cálculo de la divisa que condujo a una devaluación del rmb de 5\%, en un movimiento que fue interpretado como una medida para fortalecer el desempeño de las exportaciones, supuestamente derivado de un debilitamiento en el ritmo de expansión de la economía china. Esto acentuó la salida de capitales, con una fuerte pérdida de reservas en el Banco Central chino, temor que se transmitió al conjunto de las bolsas mundiales. Las pérdidas en las bolsas chinas fueron devastadoras, equivalentes al tamaño de la economía de Japón, con impactos que se transmitieron a las bolsas mundiales (El País, 2016). Miles de empresas chinas 
perdieron millones de dólares en capitalización, millones de inversionistas perdieron sus ahorros, en tanto las autoridades perdieron capital político, una vez que el público aprendió que las autoridades no eran infalibles y que las crisis financieras también podrían producirse en China.

El recuerdo de la crisis bursátil de agosto 2015 está fresco en la memoria de las autoridades chinas y por ello es que buscan un equilibrio manejable entre apertura y regulación, el que ciertamente no es del agrado de los bancos y entidades financieras del exterior. Por cierto, la economía china tiene diferencias marcadas con las occidentales, de modo que su capacidad de intervención y corrección a través del manejo coordinado de todos los bancos y agencias estatales es mayor que el de sus congéneres occidentales, sin embargo, revivir otra crisis en las bolsas chinas, con su correlato de devaluación del RмB, sería lo menos apropiado en este momento de amenaza de crecientes guerras comerciales.

vi.- Mayor apertura en sector automotriz chino: Una presión adicional de EE.uU. es conseguir una mayor apertura del mercado chino a las exportaciones de vehículos norteamericanos. No es evidente que esta demanda sea muy relevante para las principales empresas norteamericanas del rubro, pues todas ellas están ya ubicadas en China y, de hecho, venden más unidades por año en el mercado chino que en el norteamericano. General Motors vende 3 millones de vehículos anuales en Estados Unidos y 4 millones en China (Lardy, 2018).

Más bien estas empresas norteamericanas estarían más interesadas en flexibilizar el aparataje regulatorio en China, eliminando o reduciendo lo que algunas de ellas denuncian como sesgo en contra de las empresas extranjeras.

"There's no question that over the last 20 years that we've been carrying out this survey that things have improved, and in fact it seemed like China was on a trajectory to be more open, be more market based and to be more in line with international trade rules and regulations," AmCham Chairman William Zarit said in a Bloomberg Television interview. "But, that seems to have stopped" (Bloomberg, 2018a).

\section{B. Los alegatos chinos}

i.- "Economía de mercado": Cuando China ingresó a la omc en 200I, se le impuso el status especial de "economía en transición", aludiendo a que no contaba con una economía de mercado, otorgándosele un trato similar al que se concedió a las economías europeas previamente vinculadas al CAME, en el bloque soviético. Este dato fue crucial para las acusaciones antidumping (AD) que los socios de la omc pudieran establecer en contra de productos chinos, pues los precios de estos no estarían respondiendo a condiciones de mercado. Siendo así, en las acusaciones $\mathrm{AD}$, el país afectado podría usar los precios de un tercer país para 
calcular la magnitud del daño a su producción local.Esto abría la posibilidad de tomar el dato del país más ineficiente en ese producto, el de mayor costo, de modo de amplificar la diferencia con el menor valor del producto chino y aplicar el antidumping por esa diferencia. Este status especial concluyó el II de diciembre de 2016 y China esperaba que, de ahí en adelante, no se le aplicase ese trato discriminatorio.

Sin embargo, el propio I2 de diciembre de 2016, el Secretario de Comercio de Ee.uu. señaló que no veía motivos para cambiar su política en este ámbito ni tampoco detectaba reglas internacionales que lo fuercen a ello. El mismo I2 de diciembre 20I6, China solicitó consultas con Estados Unidos y con la UE en la omC respecto de la forma de utilizar el AD. El tema sigue pendiente.

ii.- Archivar el tema de "manipulación cambiaria": Este es un tema muy presente en el debate norteamericano pero, en rigor, en lo que respecta a la evolución del RMB, es un fenómeno que dejó de acontecer hace ya varios años. De hecho, cuando en octubre 2016 el FMI incorporó el renmimbi (RMB) en la cesta de monedas que componen los Derechos Especiales de Giro, ratificó que la cotización del RMB respondía a fuerzas de mercado. Con esta medida se avalaba el proceso gradual de liberalización de los movimientos financieros y cambiarios. En abril de 20I7, el Departamento del Tesoro norteamericano emitió su informe sobre la política cambiaria china, donde se especificaba que China no calificaba como una economía "manipuladora de su tipo de cambio”.

Es cierto que entre 1980 y 1995 , el RMB sufrió una depreciación dramática $(68 \%)$, pero desde esa fecha en adelante es la revaluación lo que ha primado. De hecho, de acuerdo a cifras del FMI, el RмB se ha apreciado $25 \%$ respecto del dólar entre 2005 y 2015 . Esto explica que el superávit en cuenta corriente de China haya caído desde un IO,I\% de PIB en 2007 a un $2,7 \%$ en 2015 y $0,2 \%$ en $2018^{5}$. Si a ello agregamos un incremento sorprendente en el salario mínimo ( $15 \%$ de incremento anual entre 2000 y 2013 ), es claro que China dejó hace varios años de caracterizarse por exportaciones intensivas en mano de obra barata y favorecidas además por una depreciación artificial de la moneda.

En cada mes de abril, el Departamento del Tesoro de EE.uU. debe presentar un informe al Congreso norteamericano respecto de la política cambiaria de sus principales socios comerciales. En el último informe de abril 2018 se estipula claramente que

5 Ayudaría más a las exportaciones norteamericanas que Trump se preocupase por revertir la escasez de demanda y el anémico crecimiento en Europa ("savingglut"), lo que tiene como uno de sus factores a elevados superávit en cuenta corriente en las economías del norte: Alemania $(7,7 \%$ del PIB); Suiza $(8,7)$; Holanda $(9,6 \%)$; Dinamarca $(6,3 \%)$; Noruega $(7,4 \%)$ (The Economist, July 28th. 20I8, p. 68). 
China no califica para ser considerada en la categoría de "manipuladora cambiaria". Lo relevante aquí es que esta instancia utiliza un criterio objetivo para esta medición y presenta sus cálculos de modo transparente. Se examinan los últimos cuatro trimestres en base a tres criterios: i) un superávit comercial en bienes pronunciado con EE.UU. (superior a US $\$ 20$ mil millones, aproximadamente un $0,1 \%$ del PIB norteamericano); ii) un superávit en cuenta corriente superior al 3\% del PIB, y iii) una persistente intervención cambiaria durante los últimos cuatro trimestres, por un monto superior al $2 \%$ del pib del país respectivo. Con base en el primer criterio, calificarían China, México, Japón, Alemania, Italia, India y Corea del Sur, entre otros. En el segundo criterio solo Japón, Alemania, Taiwán y Suiza. En el tercero, ninguno. Como el criterio del Departamento del Tesoro, de acuerdo a una ley aprobada en el Congreso, exige que simultáneamente se cumplan los tres criterios, la conclusión es clara: ninguno de los socios comerciales de Estados Unidos puede ser acusado de manipulación cambiaria (Departament of Treasury, 20I8, ps. 26-29).

iii.- Importaciones de tecnologías avanzadas y bloqueo a inversiones chinas en EE.UU.: Más allá de la guerra de los aranceles, el objetivo básico de Trump apunta a dificultar el avance chino en materia de ciencia y tecnología. En particular, esta inquietud ha surgido después de conocer la iniciativa Made in China 2025, en la cual China busca construir liderazgo global en ro áreas críticas, incluyendo tecnologías de información, robótica, aeroespacio, vehículos eléctricos, biotecnologías e inteligencia artificial.

Para ello, la administración Trump propuso actuar en dos ámbitos: i) barreras a la inversión china en empresas norteamericanas de alta tecnología; ii) bloqueo a las exportaciones norteamericanas de alta tecnología dirigidas a China. Para lo primero, el Departamento del Tesoro aplicaría una normativa que prohíbe compra de empresas tecnológicas e impone un techo de $25 \%$ a la propiedad de inversionistas chinos en empresas norteamericanas de "tecnologías industrialmente significativas", y ese techo puede variaren función de consideraciones especiales. A su vez, el National Security Council y el Departamento del Comercio están desarrollando programas para reforzar el control de estas exportaciones, particularmente las dirigidas a China.

Como es comprensible, la postura china alega el derecho a poder invertir libremente, sin restricciones administrativas o de índole político. El argumento norteamericano alude al hecho que la frontera entre la inversión privada y el Estado en China sería demasiado tenue y, por ende, cualquier inversión china en EE.uu. tendría detrás al Estado. De allí que estimen que bloqueándole el acceso a las tecnologías de punta desarrolladas en Estados 
Unidos limitarían el avance de la iniciativa Made in China 2025.

Es interesante reseñar que, ante esta escalada, Wall Street tuvo una brusca reacción a la baja, seguida por caídas similares en las principales bolsas internacionales. Esto obligó a que el Secretario del Tesoro y Peter Navarro, asesor en comercio de Trump, salieran a calmar los mercados. Navarro y Lightizer querían ir más lejos: invocar un estatuto de los 70 's, utilizado contra Irán y Corea del Norte que permite declarar "emergencia económica nacional”. Trump estaba de su lado, pero la reacción de Wall Street hizo que cambiara de opinión.

El gobierno hubo de retroceder y anunció que solo reforzaría la legislación vigente. Esta legislación permite bloquear adquisiciones pero no los joint-ventures. La nueva legislación sí lo permitiría, junto con permitir monitorear inversiones minoritarias en start-ups en sectores tecnológicos claves y exportaciones en tecnologías con potencial de uso militar.

iv.- El alegato chino en lo general: La argumentación china alega un seguimiento de las reglas de la omc, desde su ingreso en 200I. Desde esa época ha firmado 16 acuerdos de libre comercio y se ha incorporado a instancias como APEC, el G-20 y otros, sin haber recibido reclamos por su comportamiento. Declara que en 2010 cumplió plenamente con los objetivos de liberalización comercial que comprometió en la омC, reduciendo sus tarifas desde $15.3 \%$ en 200 I a $9.8 \%$ en 20I0, con reducciones posteriores en los años recientes. En enero de 2005 habría relajado todas sus barreras no arancelarias, tales como cuotas de importación y licencias de importación. En marzo de 2018 habría eliminado $44 \%$ de las revisiones y aprobaciones administrativas. En julio de 2018 habría entrado en vigor la lista negativa en inversiones extranjeras, liberalizando su ingreso, en particular, en servicios y prácticamente completando la apertura en manufacturas. Se esperarían aperturas adicionales para la inversión extranjera en agricultura, energía y recursos naturales. En materia de propiedad intelectual, se argumentan los siguientes avances: i) fortalecimiento del sistema legal y de vigilancia en la protección de los derechos de propiedad intelectual; ii) establecimiento de tres cortes de propiedad intelectual (Beijing, Shanghai y Guangzhou); iii) se combate con firmeza la piratería online; iv) se reestableció el Consejo Nacional de Propiedad Intelectual; v) se revisó la Ley de Marcas Comerciales, reforzándolas e introduciendo un sistema punitivo de compensaciones; vi) se revisó y actualizó la Ley de Competencia Desleal, y vii) se ha hecho más expedito el proceso para revisar la Ley de Patentes y de Derechos de Autor (Lian Ming, 20I8).

Como muestra del impacto de estas políticas, se arguyen los siguientes resultados: i) desde 200I, los royalties que China ha cancelado han crecido a un $17 \%$ anual, alcanzando los US $\$ 28,6$ mil millones en 20I7; ii) en 
20I7, se presentaron I,38 millones de patentes en China, un Io\% de las cuales correspondieron a empresas extranjeras (Lian Ming, op.cit.).

\section{LAS POSIBLES RESPUESTAS CHINAS}

A.- Fortalezas chinas: La fortaleza china opera más por el lado productivo y comercial. Después de la crisis subprime, China viene explicando entre 30 y $35 \%$ del incremento anual del PIB mundial; es el principal mercado para las exportaciones de la UE, de Japón, Corea del Sur, Brasil y para el G-20. Por lo tanto, un menor crecimiento en China golpeará las exportaciones de todas estas economías.

China es además el hub de las cadenas de valor asiáticas y el principal socio comercial de las economías de Asia Pacífico. Dados los altos grados de integración productiva en esta zona, el castigo a las exportaciones chinas terminará siendo un castigo a los países asiáticos que aportan partes, piezas, componentes y servicios en la "fábrica china", la que finalmente ensambla los productos y los envía al exterior. Cerca del $35 \%$ de las exportaciones chinas son de ensamblaje ("processingtrade"). Por tanto, una guerra comercial con China afectaría severamente a Japón, Corea, Hong Kong y Singapur, economías que proveen a China de buena parte de los bienes, insumos y servicios que culminan siendo integrados en la "fábrica china" para ser exportados al mundo.

Por otra parte, China compra el 60\% de las exportaciones norteamericanas de soja; es el principal mercado automotriz, de PCs y celulares en el mundo. En tanto, las principales empresas de EE.Uu. y la UE están radicadas en China y podrían verse afectadas por la guerra comercial. El mercado chino para Iphones es de US $\$ 40$ b., el mayor en el mundo y China ejerce la principal demanda mundial en aviones, activando la competencia entre la Boeing y Airbus. Las 500 empresas Fortune están radicadas en China; la GM vende cada año 3 millones de vehículos en Estados Unidos y 4 millones en China.

China es además el primer acreedor de eE.uu., por la tenencia de papeles del Tesoro norteamericano y, por tanto, es también el principal financista de los desequilibrios fiscal y externo de la economía norteamericana. Hay evidencia entonces para sugerir que, en materia económica y comercial, la parte china parece estar mejor posicionada que la norteamericana para una guerra de mayor alcance.

B.- Debilidades chinas:Hasta fines de 2018 , el principal impacto de las medidas proteccionistas de Trump en contra de las exportaciones chinas se dejó sentir en las bolsas, toda vez que, luego de tales medidas, las bolsas chinas muestran importantes caídas. Así, por ejemplo, en 20I8, la bolsa de Shanghai, la más importante, tuvo una 
caída de $25 \%$ y la de Shenzhen una de $34 \%$. Con ello, las bolsas chinas perdieron el segundo lugar en el mundo, lugar que habían arrebatado a Japón a fines del 2004.

El eslabón financiero-bursátil parece ser el más débil en la jugada china. China es también el principal acreedor de EE.uu. y, por ende, a través de la compra que realiza de los bonos del Tesoro norteamericano es también el principal financista del desequilibrio externo de EE.uU. En teoría, esta posesión de títulos norteamericanos podría ser leída como un arma decisiva de China en esta contienda. Sin embargo, ello no es tan fácil. Hacer uso de esta peligrosa arma, absteniéndose de comprarlos o deshaciéndose de ellos, haría caer el precio de esos bonos, incrementándose la tasa de interés de los mismos. Esa mayor tasa de interés afectaría adversamente el nivel de actividad en la economía mundial, riesgo al que ni China ni Estados Unidos debieran estar dispuestos a correr. Los mercados financieros tenderían a leer estas maniobras como signos de endurecimiento del conflicto, acentuando las presiones a la baja en las bolsas chinas, estimulando la salida de capitales desde China.

En ese escenario de máxima tensión, la tendencia más probable es el refugio en el oro y en el dólar, con lo cual se valorizaría aún más la moneda norteamericana y se depreciaría el RMB, volviendo a complicar el déficit bilateral de Ee.uU. con China. Como las economías emergentes ya lo han aprendido, un escenario de debilitamiento en el comercio internacional, acompañado de valorización del dólar y mayores tasas de interés es la "tormenta perfecta" para desencadenar una caída en el precio de los commodities y para endurecer las condiciones de acceso al financiamiento externo. Es decir, una perfecta tijera que golpearía a estas economías en la cuenta comercial y en la cuenta de capitales.

\section{C.- Respuestas comerciales:En res-} puesta al alza de aranceles que EE.uU. ha puesto sobre productos chinos, la respuesta china ha sido retaliar las exportaciones norteamericanas en montos cuidadosamente proporcionales a los aranceles impuestos por EE.UU. y focalizados en pocos rubros, básicamente agrícolas y en condados que más favorecieron electoralmente a Trump. En la primera retaliación ejercida por China, se vieron afectados 2.783 condados y 2.279 (82\%) de ellos fueron condados donde Trump venció en las elecciones. Entre otros, Wisconsin, estado de Paul Ryan, speaker de la Cámara, y Kentucky, estado de McConell, líder republicano del Senado ${ }^{6}$.

Adicionalmente, China ha rebajado aranceles a la soja proveniente de países vecinos: Corea del Sur, India, Bangladesh, Laos y Sri Lanka. Levantó las prohibiciones sobre importaciones

6 La retaliación abre espacio a otros proveedores. Por ejemplo, España, principal proveedor de carne de cerdo enfrenta aranceles de I $2 \%$ en carne congelada y $20 \%$ en miel fresca, mientras EE.UU. enfrentará aranceles de $37 \%$ y $45 \%$, respectivamente. 
de carne de cerdo de Francia y Reino Unido, restricción que venía del tema de las "vacas locas" de los años $90^{\prime} \mathrm{s}^{7}$. También China rebajó aranceles en químicos, agropecuarios, ropa, metales no ferrosos, gas licuado y redujo la lista negativa para el ingreso a la IED de 63 a 48 subsectores, eliminando o reduciendo el límite a la propiedad extranjera en sectores como la construcción aeronáutica y naval, redes eléctricas, infraestructuras, minería, gasolineras, comercio de cereales. Es cierto que aquí hay una combinación de medidas probablemente inducidas por las medidas coercitivas de Trump y otras que se relacionan con el ritmo de las reformas económicas en China. En cualquier caso, también parece probable que dicho ritmo haya recibido un estímulo especial en el marco del conflicto comercial con EE.uU., buscando ganar aliados europeos y asiáticos, por un lado y, por otro, dando muestras de apertura comercial y de inversiones en contraposición al discurso proteccionista de Trump.

D.- Ampliando el arco de las alianzas: Mientras Estados Unidos le impone barreras a las exportaciones de sus principales aliados, China busca

7 Estas medidas tampoco conversan mucho con la омс, pues la rebaja selectiva de aranceles a la soja de algunos países solo estaría permitida si es que ello respondiese a preferencias negociadas en acuerdos de libre comercio. Permitir ahora las importaciones de carne de cerdo desde Francia y el Reino Unido bien podría ser una coincidencia, aunque la probabilidad de ello es más bien baja. ampliar su arco de alianzas en torno a un discurso de defensa del multilateralismo. Esa defensa y renovación del multilateralismo estuvo presente en la reciente Cumbre UE-China a mediados de julio de 20I8, donde se gestó un Grupo de Trabajo en torno a esta temática. China aspiraría a presentar una alianza con la UE en defensa del multilateralismo, entablando incluso acusaciones conjuntas en la OMc en contra de las medidas comerciales de Trump. Para la UE, esto no es fácil y no solo por el eventual costo político que le podría significar una alianza UE-China, enfrentando a EE.UU., sino también porque comparte con este país varias de las críticas a la política comercial y de inversiones de China.

El combate al proteccionismo también estuvo presente en la Cumbre CEEC (Central and Eastern EuropeanCountries), la Cumbre I6+I, realizada en Bulgaria a inicios de julio de 2018. Este bloque incluye II estados miembros de la UE (Bulgaria, Croacia, Eslovaquia, Eslovenia, Estonia, Hungría, Letonia, Lituania, Polonia, República Checa, Rumania); 5 países balcánicos (Albania, Bosnia Herzegovina, Macedonia, Montenegro y Serbia) más China. En esa reunión, el Primer Ministro chino anunció una línea de crédito cercana a los US $\$ 3.500$ millones para proyectos enmarcados en la iniciativa de la nueva Ruta de la Seda (carreteras, 
puertos, parques industriales, centrales eléctricas, redes de fibra óptica) ${ }^{8}$.

En el mes de junio de 20I8, en la ciudad china de Qingdao, se realizó la Cumbre Anual de la ocs (Organización de Cooperación de Shanghai), instancia que desde el año 2000 congrega como socios fundadores a China, Kazajistán, Kirguistán, Rusia, Tayikistán y Uzbekistán, más la presencia de India y Pakistán, quienes se integraron como miembros plenos en 20I7. En esta reunión, junto con comprometerse a combatir el unilateralismo y el proteccionismo comercial, se establecieron compromisos de cooperación en facilitación de comercio, seguridad y movimiento de personas. Los países de la ocs representan algo más del 60\% del territorio euroasiático, casi la mitad de la población mundial y más del 20\% del PIB global.

\section{E.- Ejes claves en la estrategia} china: El principal objetivo chino es seguir avanzando en su estrategia 2050, momento en que se produciría "el retorno a la normalidad histórica", esto es, el Imperio del Centro volvería al centro de la economía mundial. Ello exige evitar la llamada "trampa de Tucídides”, es decir, el conflicto con EE.UU. Desde esta lógica de largo plazo, en mi opinión, el desafío de la política china es administrar el conflicto con

8 Según datos de China Railway Corporation, en seis años, un total de 7.89I trenes de mercancías han unido China y Europa Central, en tanto la red ferroviaria enlaza 43 ciudades chinas con 42 europeas en I4 países (Efe, 20I8).
Estados Unidos, sin cerrar las puertas a la negociación.

Administrar el conflicto tiene varias dimensiones. En lo comercial, se trata tanto de construir mecanismos de defensa frente a las menores exportaciones que China estará enviando a EE.UU. como de replicar con medidas de retaliación comercial u otras que causen daño económico y político a la administración norteamericana. El principal mecanismo de defensa es contar con una política fiscal que active la inversión pública en infraestructura, estabilizando la tasa de crecimiento del pib. También puede considerar mecanismos de promoción de exportaciones que desvíen las exportaciones que iban hacia EE.UU. en dirección a otros mercados, si bien esta opción tendrá un aporte marginal, considerando tanto las dimensiones del mercado norteamericano, nada de fácil de sustituir con varios otros mercados, como el hecho que las exportaciones chinas ya son dominantes en muchos de ellos.

El principal desafío en la administración del conflicto es evitar shocks macro-financieros desestabilizadores, lo que probablemente constituye el eslabón débil de la estrategia china. La experiencia de agosto 2015 en China es suficientemente aleccionadora respecto del rol desestabilizador que pueden jugar malas noticias en la bolsa o en la variación del tipo de cambio. Desde este punto de vista, Trump tiene una ventaja, pues los mercados financieros y las principales bolsas aún no se 
convencen de la gravedad del conflicto comercial EE.UU.-China y continúan con elevados rendimientos. Los buenos resultados de la economía de Estados Unidos en 2018 reavivan el entusiasmo y, hasta ahora, le confieren espacio a Trump para movidas adicionales. Las autoridades chinas tienen menos leverage en estos temas y, por tanto, pequeñas oscilaciones cambiarias $o$ bursátiles podrán inducir a una marcada volatilidad financiera, incluyendo fuertes movimientos de capitales.

Un tercer eje, admitiendo que el conflicto será de larga duración, es ampliar el arco de alianzas, como ya se indicó más arriba. Aquí el principal objetivo es estrechar posiciones con la UE y otros aliados del G-20, particularmente con Japón y Corea del Sur, así como mejorando el vínculo con Australia y Nueva Zelanda, el que se ha deteriorado en el último tiempo. Lo mismo con Canadá.

Para Xi es fundamental que estos nubarrones en la relación con EE.UU. no afecten las perspectivas de la iniciativa овоR ni la de Made in China 2025 , dado que ellas son las rutas que la conducen a su meta de largo plazo. Si al final del año 20I8, China pudo mostrar que su ritmo de crecimiento en lo esencial no ha sido afectado; que su macroeconomía y finanzas siguen bajo control; que la iniciativa de la Ruta de la Franja y la Seda sigue avanzando y que el objetivo Made in China 2025 tampoco se ha visto retrasado, entonces está en condiciones de decir que las agresivas políticas de Trump no le están haciendo mella.

Por ello es que la iniciativa china puede remitirse a resistir durante 2 años, esperando la próxima administración norteamericana, tratando de jugar cartas eficaces de corto plazo, buscando que productores agrícolas, cámaras empresariales y empresas norteamericanas radicadas en China puedan hacer valer sus temores a la guerra comercial en las elecciones presidenciales de 2020. Por de pronto, el control demócrata en la Cámara de Representantes le resta variables de holgura a Trump. Hay aquí una ventaja que el sistema político chino le brinda a $\mathrm{Xi}$, dado que el espacio institucional para las críticas es menor en China y además Xi no enfrenta el desafío de elecciones legislativas cada dos años y presidenciales cada cuatro.

Por último, en el debate norteamericano crece la inquietud por una desaceleración más marcada en la economía norteamericana, no descartándose la posibilidad de una recesión a fines de 2019 o inicios del 2020. Las proyecciones del FMI de enero de 2019 indican que tras haber crecido $2,9 \%$ en 20I8, la economía norteamericana crecería solo 2,5\% en 2019 y I, $8 \%$ en 2020. Estos resultados estarían bien lejos del $4 \%$ anual que prometió Trump al asumir la presidencia. Si estos fuesen los resultados económicos de Trump, el promedio de crecimiento de su período sería de 2,3\% anual, cifra nada de distinta al promedio de Obama, lo que 
ciertamente desalentaría bastante a los grandes inversionistas.

\section{El arte de las guerras Comerciales: escenarios Posibles?}

Aquí examino la disputa comercial Estados Unidos-China con una mirada de largo plazo, buscando definir los escenarios posibles en la evolución del conflicto y - con el bagaje de un principiante de Occidente-, aplicar algunos de los preceptos clásicos de la cultura china al actual conflicto.

Como singular dato previo, vale la pena insistir en que, tras el camuflaje de una guerra comercial, lo que está en juego es un conflicto (o guerra larvada) por las tecnologías y el conocimiento del siglo xxi. Esto quiere decir, como eje ordenador del debate, que este conflicto no concluirá pronto; ni siquiera luego que se marche Trump de la Casa Blanca. Este conflicto nos acompañará durante las próximas décadas, ya que tiene que ver con los poderes relativos en las tecnologías del futuro. Subrayo este dato para que no se lo minimice cuando estemos describiendo las fases del conflicto "comercial".

a) El arte de la guerra: "El arte de la Guerra", atribuido a SunZi, es uno de los textos clásicos de la cultura china. Kissinger lo describe como un texto básico sobre estrategia, diplomacia y guerra, y como uno pionero en

9 En este punto, agradezco los comentarios de Roberto Zahler. conseguir la victoria por medio del conocimiento psicológico, evitando el conflicto directo, constituyéndose así en una clave de la realpolitik china (Kissinger, 20I2, pgs. 42-52) ${ }^{10}$.

Con el perdón anticipado que solicito a los lectores, aplicaré algunos de los conceptos del maestro SunZi a las escaramuzas del actual conflicto comercial entre EE.uU. y China, de acuerdo a cómo Trump lo ha definido: "una guerra comercial"

En la visión de Sun, (SunLizong, 20I5) hay cinco claves que examinar en la disposición de dos "ejércitos" en combate:

I. La política, la moral y la ética (vínculo entre pueblo y autoridad), es decir, hasta qué punto el líder es acompañado, comprendido y apoyado por su pueblo.

2. La dimensión temporal, es decir, en qué momento histórico acontece el ataque (ciclo de la economía mundial y de China y Estados Unidos; situación política en cada lado; fortalezas comerciales, económicas y financieras de cada parte).

3. La configuración del terreno en que acontece el conflicto (ventajas

10 Henry Kissinger, “China”, Debate, Random House Mondadori S.A. Barcelona, 2012. 
comparativas de cada lado; estructura de alianzas).

4. Los "generales" y la jefatura militar, es decir, la inteligencia estratégica y la visión de conjunto del liderazgo. 5. El sistema legal e institucional, esto es, cómo funcionan los organigramas, funciones y logística de cada "ejército". Otra forma de decir lo mismo es hasta qué punto se cumplen las órdenes del alto mando de cada parte en términos de rapidez y eficacia.

Con base en esas claves, es posible analizar el estado comparativo de siete vectores que medirían el poder relativo de las fuerzas de cada adversario.

\section{Siete vectores comparativos para evaluar la fuerza relativa de cada bando}

1. Política más sensata, con mayor apoyo

2. Capacidad y competencia del liderazgo

3. A quien favorece el tiempo y las condiciones del terreno

4. Cumplimiento de normativas legales

5. Superioridad en fuerzas militares

6. Preparación de "oficiales y soldados" (oficiales de gobierno y empresas)

7. Sistema de premios y castigos más eficaz.

Fuente: SunLizong, El arte de la Guerra de SunZi”, Casa Editora Hua Yi, Beijing, 20I5.

Del análisis ponderado de estas 5 claves y 7 vectores, es posible deducir qué adversario está mejor preparado para un conflicto en este caso comercial. Un recorrido por las 5 claves y los 7 vectores me lleva a pensar que China se ve mejor preparada que los Estados Unidos de Trump para un conflicto comercial que pueda prolongarse más allá de 20I8. En particular, destacaría que el líder Trump tiene un menor grado de apoyo interno político y empresarial que $\mathrm{Xi}$; que la dimensión temporal con que EE.uU.y China abordan el conflicto favorece a quien lo haga con la mirada de más largo plazo, en este caso, China; que la inteligencia estratégica y la capacidad de aunar aliados también acompaña más a Xi y que el sistema legal e institucional permite reacciones más rápidas y eficaces en el caso chino. Me parece que el único 
punto que favorecería a Trump es el de "superioridad en las fuerzas militares", aplicadas esta vez a la hegemonía del dólar en las finanzas internacionales y a la solidez de las bolsas de valores. En efecto, aquí es donde parece radicar la mayor debilidad china: su vulnerabilidad frente a movimientos bruscos en la paridad del Rмв con el dólar; el temor a una salida brusca de capitales y a movimientos desestabilizadores en las bolsas chinas.

\section{b) Escenarios posibles en la gue-} rra comercial: Una forma esquemática - y, por cierto, incapaz de capturar todas las opciones posibles- nos puede ayudar a entender las opciones más polares que están en juego. Entre otras cosas, la simultaneidad de impactos comerciales y financieros impide graficar los escenarios posibles en un cuadro de doble entrada. Por otra parte, las medidas comerciales o financieras pueden variar en intensidad y cobertura, de modo tal que un anuncio poderoso en el titular puede significar un efecto nimio o una medida poco destacada que pudiese tener un impacto considerable. Con todo, es posible aproximarse a algunas conclusiones preliminares.

Veamos primero algunas variables que podrían estar detrás de cada respuesta de China y de Estados Unidos.
China podría ceder si la desaceleración en su economía es demasiado severa; si aparecen impactos desestabilizadores en las bolsas de valores chinas o si el RMB se deprecia brúscamente respecto del dólar, generando un importante flujo de salida de capitales. Cualquiera de estos impactos reduciría el apoyo interno a Xi y lo llevaría a buscar espacios viables de negociación.

Trump estaría más dispuesto a ceder si es que la economía norteamericana se desacelera, la bolsa sufre impactos importantes, su apoyo en los distritos agrícolas se ve muy afectado por los mayores aranceles que ha colocado China en respuesta a los mayores aranceles que ha utilizado Trump en contra de productos chinos. Aquí lo interesante es que el impacto no afecta únicamente a aquellos productores que exportan a China, sino a todos los que producen o intermedian el producto que enfrenta mayores aranceles chinos. Así, por ejemplo, el precio de la soja en Estados Unidos ha caído 20\% desde el inicio del conflicto comercial, afectando a quienes exportan a China, a otros mercados y también a quienes venden en el mercado norteamericano. En la medida que crezca la molestia de los agricultores afectados, crecerá también el distanciamiento de los legisladores republicanos respecto de las políticas comerciales de Trump. 


\section{Escenarios posibles en la guerra comercial}

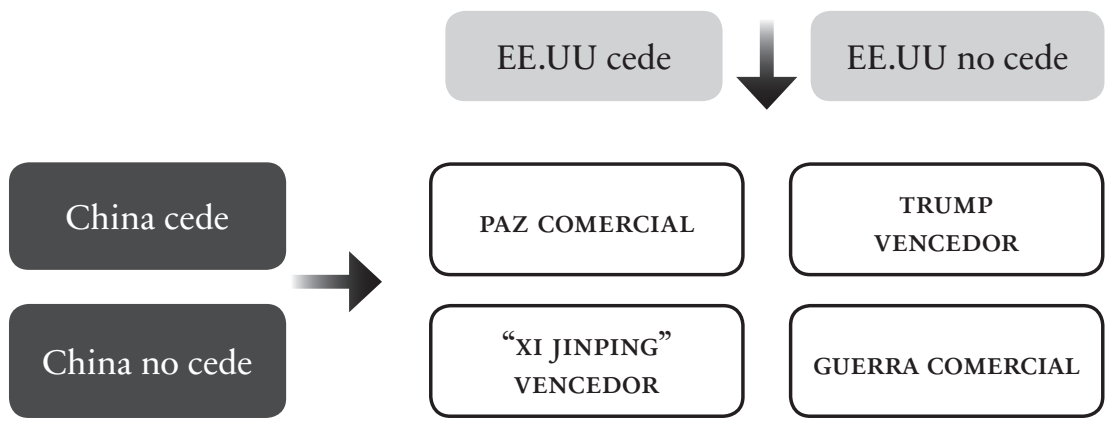

Considerando la intensidad y cobertura de las medidas proteccionistas en vigor por ambos lados, así como los plazos en que podrían entrar en vigor, la probabilidad del Escenario I (Paz Comercial), en que Ee.uU. y China ceden, es más bien baja. En efecto, un objetivo clave de Trump es promover una imagen fortalecida para convencer al electorado que su consigna "America great again" se está imponiendo y para ello vender la imagen de victoria en la relación con China es fundamental. De la misma forma, frente a un plazo más bien breve y medidas que afectan solo marginalmente el comercio exterior y el PIB chino, es poco probable que China pueda ceder en el corto plazo.

Por razones parecidas, descarto el Escenario 4 (Guerra Comercial), donde ambos gobiernos insisten en agudizar el conflicto, escalándolo y abarcando nuevos ámbitos, tales como la inversión, las finanzas y los tipos de cambio. La probabilidad de este escenario es baja, porque conduciría a una recesión en la economía mundial, probablemente acompañada de una crisis financiera global. Esta última crisis podría incluso ser de mayor magnitud que la crisis subprime, dados los elevados niveles de valorización bursátil que han sido impulsados por la generosa liquidez en EE.uU. y en la UE, por una parte, y por otra, porque las autoridades económicas de Occidente contarían con un limitado stock de instrumentos monetarios y fiscales para abordar la crisis. En efecto, dados los históricamente bajos niveles de la tasa de interés y la subsistencia de un elevado déficit fiscal en EE.uU. (4,6\% PIB en 20I8), hay menos margen que en 2008 para bajar la tasa de interés y para aumentar el gasto público para ir en auxilio del sistema financiero y reactivar la economía. Por lo tanto, si se llegase a avanzar en la dirección de ese escenario, surgirán reacciones en EE.Uu. desde el sector empresarial, del Congreso, del sistema financiero y de 
los organismos internacionales y sería difícil para la Casa Blanca resistir esta presión conjunta.

A su vez, para la parte china este escenario de intensificación del conflicto comercial tampoco le ayuda por varias razones. Una razón es que en este escenario se superpondrían los efectos comerciales y financieros, siendo estos últimos de más difícil administración. En segundo lugar, en este escenario, China se verá presionada a desarrollar planes económicos de emergencia, los que tenderán a focalizarse en inversión en infraestructura de rápido impacto sobre el empleo y la actividad económica.

Si hay algo que China ha demostrado saber hacer bien, es crecer a tasas elevadas. El problema es que como ya lo mencionó Wen Jiabao en 2013 , ese modelo de crecimiento estaba agotado. Retornar a un patrón de crecimiento elevado, explicado por ingentes inversiones en infraestructura, inversiones de baja rentabilidad social ("edificios fantasmas"), realizadas por empresas estatales, que se financian endeudándose en bancos estatales, todo ello contribuiría a agravar la deuda pública de gobiernos locales y regionales, alimentaría la burbuja inmobiliaria, reduciría la exposición a la competencia de las empresas estatales, haciendo más difícil la lucha contra la corrupción y el avance en innovación y productividad. Este accionar podría efectivamente compensar los efectos recesivos de la pugna comercial, pero apartaría a las autoridades del camino de las reformas económicas, esto es, favorecer el consumo doméstico, mejorar la eficiencia de la inversión, racionalizar las empresas públicas, fusionándolas y mejorando su eficiencia, eliminando las “empresas zombies", favorecer la innovación y las metas del programa Made in China 2025.

Se ha argumentado que la elevada posesión de bonos norteamericanos en manos del BC chino sería un arma poderosa que China podría utilizar en su favor, en caso de agudización del conflicto.

En mi opinión, ello es un argumento a medias. Efectivamente China es el principal acreedor de Estados Unidos. Sin embargo, no se infiere de ello que esa sea un arma que se pueda utilizar a discreción. Imaginemos que, dada una agudización del conflicto, el BC chino decide vender una cantidad importante de estos títulos. Ello llevaría a un menor precio de los bonos y a un incremento en la tasa rectora del sistema financiero internacional, lo que se propagaría a la economía mundial. Si ese incremento fuese considerable, podría transmitir presiones recesivas a la economía global y a las principales bolsas de valores. Ello también conduciría a una valorización del dólar y a una caída en dólares del precio de los commodities. El escenario resultante sería aflictivo para las economías emergentes, particularmente para aquellas con mayor necesidad de financiamiento externo. Al afectarse las bolsas globales y apreciarse el dólar, el efecto sobre el RмB sería a 
la depreciación, acentuando temores de salidas de capital, las que eventualmente podrían concretarse. Vale decir, darse el gusto de presionar a la economía estadounidense, podría afectar el dinamismo de la economía global, por una parte, y por otra, también podría afectar la estabilidad financiera y la posición de reservas de la propia economía china. Debe ser, por tanto, una herramienta que debe calibrarse bien antes de utilizar.
Con base en estas especulaciones, me parece que en los próximos años, 2019-2020, los escenarios más probables se ubiquen en las cercanías de los cuadrantes 2 y 3 . Sin embargo, tampoco es viable esperar una rendición de ninguno de los dos contendientes. Por tanto, lo que asoma como más previsible es un lapso largo en que se transitará desde el Escenario 2 (donde China cedería) al Escenario 3 (donde sería EE.UU. quien cedería).

\section{Escenarios posibles en la guerra comercial}

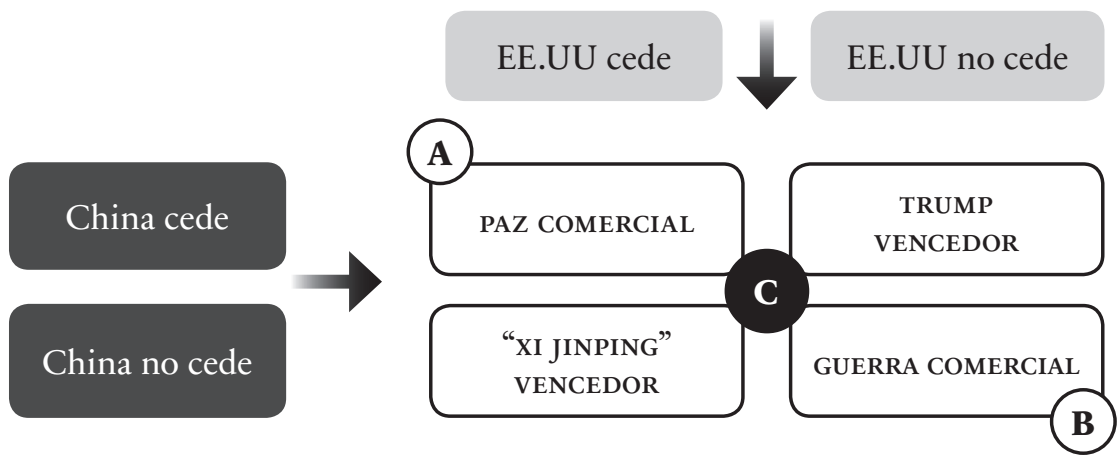

Estos cuadrantes no son estáticos, más bien, los eventos se desplazan por el área indicada en cada uno de ellos en una zona irregular que abarca desde A, el punto de mayor paz comercial, al punto $B$, que refleja la máxima confrontación. Entre ambos puntos hay innumerables posibilidades, pudiendo la curva desplazarse hacia los cuadrantes 2 y 3 en distintos momentos del conflicto. De este modo, es posible esperar que el grueso de los eventos se estructure en una nube de puntos posibles en las cercanías del punto $\mathrm{C}$, el punto central, desplazándose en dirección a cualquiera de los cuadrantes, en distintos momentos del conflicto. Eso es lo que se refleja en el Gráfico 2 en la zona que rodea al punto $C$, esto es, desplazamientos en niveles variados de conflicto, otorgando victorias 
parciales a uno y otro lado, con avances y retrocesos también compartidos.

De lo anterior se infiere que estaríamos frente a un conflicto de larga duración, de intensidad variable, donde será difícil detectar vencedores netos y donde las victorias/derrotas serán parciales, transitorias y donde el sello vencedor irá cambiando de bando. Amenazas y contra-amenazas, implantación de medidas que se anuncian, pero que entrarían en vigor en varios meses más; medidas que entran en vigor, pero solo en una fracción de la amenaza inicial; retoma de conversaciones, congelamiento de las mismas y nueva amenaza de medidas proteccionistas. Este parece ser el ciclo más probable para las relaciones comerciales entre EE.UU. y China para los próximos años del mandato de Trump.

Un punto clave es precisar dónde estarían las líneas rojas de cada actor en pugna, es decir, el tema en que no se está dispuesto a transar. En el caso norteamericano esto es difícil de definir, pues Trump ha planteado una serie amplia de objetivos en la guerra comercial contra China (el déficit comercial; el "robo" de propiedad intelectual; la sobreproducción en sectores claves; los subsidios estatales a las empresas; mayor apertura en servicios financieros, etc.), sin precisar sus prioridades. De las declaraciones de Peter Navarro y Lighthizer, el actual USTR, queda más claro que el gran objetivo es dificultar y frenar el avance tecnológico de China. Sin embargo, la personalidad de Trump no admite demasiadas precisiones en este ámbito, pues bien podría ser que eventos menores en el comercio o la inversión bilateral desaten en él reacciones destempladas que podrían causar turbulencias en los mercados. Así, por ejemplo, cuando la economía global y los mercados financieros se encontraban procesando los datos del entrevero comercial con China, Trump ha reaccionado con medidas proteccionistas en contra de Turquía, por temas no económicos, desatando turbulencias financieras que no estaban incorporadas y, de paso, poniendo cuesta arriba la recuperación del crecimiento en Grecia; la salud de varios bancos europeos con activos comprometidos en Turquía, y el financiamiento de los desequilibrios en cuenta corriente en Argentina, Pakistán y Turquía, entre las economías emergentes.

En el caso chino, me parece que la "línea roja" incluye varios elementos: i) la carrera por los avances en tecnología e innovación; ii) la inversión china en el exterior; iii) la estabilidad política y económica interna.

En materia de ciencia, tecnología e innovación, los líderes chinos tienen claro que la decadencia partió cuando China dio la espalda a la Revolución Industrial, a mediados del siglo xviII, rezagando su tecnología naval y militar, circunstancia que permitió la invasión inglesa (Guerra del Opio, I84I) y la firma de una saga de tratados colonialistas donde Inglaterra, 
Francia, Alemania, Estados Unidos, Japón y Rusia, se apropiaron de territorios y riquezas chinas, período que los chinos recuerdan como "el siglo de la humillación” y que solo culminó en 1949, con el triunfo de la revolución y la instauración de la República Popular China.

Esta vez, en presencia de la llamada 4a Revolución Industrial, China no está dispuesta a bajarse del carro de la innovación y el cambio tecnológico. $\mathrm{Al}$ contrario, su objetivo es encabezar este proceso en 2050 , es decir, cuando se cumpla un siglo de la instauración de la nueva república. Ese es el "sueño chino". Esta y no otra es pues la "línea roja" de China.

En mi modesta opinión, China podría estar dispuesta a aceptar una menor velocidad o incluso retrocesos parciales en aras de este objetivo, pero lo que China no aceptaría es abandonar este objetivo de largo plazo. De este modo, si la postura norteamericana fuese más pragmática, podría plantearse objetivos más acotados y buscar formas de complementariedad con la emergencia china, fenómeno que da la impresión que Estados Unidos podrá demorar y obstaculizar durante algunos años, pero al que, finalmente, deberá acomodarse ${ }^{11}$.

11 Por cierto, siempre estará presente la posibilidad de un conflicto creciente, escalando hasta la esfera militar. Esa opción trasciende de lejos la dimensión económica y la analizo en un texto en preparación.
La inversión china en el exterior es otro elemento clave del "Sueño de Xi", expresado no solo en la iniciativa овоR, "One Belt, One Road" (en español se utiliza la expresión "la franja y la ruta"), sino también su creciente inversión en el exterior en recursos naturales, tanto en África como en América Latina. Estos recursos naturales - energía, minerales y alimentos- son cruciales para sostener el elevado ritmo de crecimiento económico, por una parte, y por otra, para atender las crecientes demandas de consumo cada vez más sofisticado que plantea la acelerada urbanización, la expansión de las capas medias chinas y el incremento en el ingreso por habitante. A su vez, la iniciativa овов les es fundamental para exportar tanto capacidad productiva excedente en sectores industriales claves (acero, aluminio, cemento, vidrios) como sus excedentes de ahorro. La expresión institucional de esta estrategia se expresa en la creación del banco brics y del Banco Asiático de Inversión en Infraestructura (BAII), iniciativas en que China tampoco está dispuesta a ceder.

La estabilidad política y económica es una prioridad a todo evento en la estrategia china. Ello es así porque el gran activo de legitimidad doméstica de la experiencia china y del propio PCCH es su capacidad de ofrecer a sus ciudadanos un escenario de elevado crecimiento y mejoría en calidad de vida, sin los traumas históricos del "Siglo de la Humillación" ni de la 
fallida industrialización forzosa del "Gran Salto Adelante" (I957-I960), ni de la traumatizante Revolución Cultural (1966-1970, aproximadamente).

La conclusión entonces es que habríamos ingresado a un período de mayor incertidumbre económica y volatilidad financiera en la economía mundial y donde ellas ya no provendrán de las consecuencias de la crisis financiera, sino de decisiones políticas conscientes. Este preocupante factor afecta el desarrollo del comercio sometido a normas internacionalmente aceptadas, cuestiona la internacionalización de las inversiones (pues ahora las somete al prisma de la "seguridad nacional"), debilita el edificio del multilateralismo comercial y deslegitima la fuerza jurídica de los tratados de libre comercio firmados por Estados Unidos, la principal economía del mundo.

\section{c) La astucia, como principio} ordenador en la estrategia de SunZi: Al especular sobre eventuales reacciones chinas a los ataques comerciales de Trump, bien vale la pena recordar otros principios de Sun, lo que listo a continuación (SunLizong, op. cit):

- Fingir incapacidad de combate.

- Aparentar defensiva u ofensiva cuando buscamos lo contrario.

- Atacar en tiempos y lugares inesperados.

- Desorientar la estrategia del adversario.

- Frustrar su diplomacia.
- Ataque frontal es siempre la última opción.

Aquí entramos de lleno en la lógica que describía Kissinger, esto es el vínculo entre diplomacia y el arte de la guerra. Kissinger nos recuerda que el ajedrez es occidental y allí se busca la victoria total, el derrumbe del rey. El juego chino de contraparte es el $w e i$, donde lo que se busca es el cerco estratégico, es decir, la batalla prolongada con ventajas relativas y acumulativas. El wei privilegia la flexibilidad estratégica y la victoria conseguida por medios psicológicos, evitando el conflicto directo. Más aún, Sun nos dice que "la superioridad definitiva es derrotar al adversario sin librar batallas". Siendo así, ¿̇cuál podría ser la respuesta china a las provocaciones de Trump?

Si las autoridades chinas siguiesen el consejo de SunZi, la reacción china no debiera ser obvia ni predecible ni en forma ni en tiempo; no buscaría la victoria total e inmediata, y realizaría un gran despliegue de medios diplomáticos. También debiera hacer primar la mirada estratégica de largo plazo.

La guerra comercial requiere al menos de dos contrincantes. La teoría económica nos dice que atacar elevando aranceles afecta la competitividad de tus empresas (bienes intermedios y de capital) o la factura de tus consumidores (bienes finales). De esta forma, el efecto empleo final puede ser negativo, lo que ya acontece en el caso del acero 
norteamericano, sector donde se protegen 385 mil empleos, pero se afectan 6,5 millones de empleos en sectores que utilizan el acero como insumo. Sin embargo, lo más relevante desde una óptica de mediano plazo es que si China y la UE reaccionan elevando aranceles a las exportaciones norteamericanas, importarán daño económico y darán un argumento a Trump para demostrar a sus electores que están "maltratando a Estados Unidos".

Recordando aquella máxima de SunZi de reaccionar como menos lo espera el adversario, mi lectura sería que la respuesta china bien podría orientarse por los siguientes lineamientos:

a. No caer en la provocación de retaliar proporcionalmente los productos norteamericanos, es decir, no seguir en una carrera estricta por elevar los aranceles en la misma proporción en que está empeñado Trump.

b. Llevar los casos a la омс y esperar allí, con paciencia oriental, los largos plazos de estas controversias.

c. Reforzar el vínculo con la UE y, en particular, trabajar en conjunto con ella una reformulación de la омc a los nuevos tiempos.

d. Abrir más espacio a la UE en la iniciativa One Belt, One Road, incluyendo bancos y empresas europeas. e. Establecer negocios conjuntos entre el AIIB (Banco Asiático de Inversión e Infraestructura) con actores europeos y japoneses.

f. Forjar una alianza China-UE-TPP-II (clave aquí el vínculo con Japón)Alianza del Pacífico-Mercosur para promover la renovación y actualización de la omc.

g. Apoyar la propuesta de la UE de conformar un Tribunal Internacional de Inversiones.

h. Ser más flexible en la negociación del RCEP (Regional Comprehensive Partnership) y concluirlo a la brevedad.

i. Reforzar sus compromisos de cooperación económica con África y con América Latina.

j. Tomar medidas unilaterales audaces que incluso la lleven a sobrecumplir sus compromisos en materia de Cambio Climático.

k. Llevar a APEC 2019 propuestas de reforma - modernización del sistema multilateral de comercio-, ojalá ya discutidas en ASEAN o en el RCEP.

Si China siguiese estas líneas de acción, reforzaría su peso internacional, su compromiso con un 
multilateralismo renovado y contribuiría a aislar los ataques proteccionistas de Trump. Una vigilancia especial habrá que mantener sobre el tema cambiario, la evolución de las reservas internacionales y de la deuda doméstica, tanto a nivel de empresas como de personas. De ese modo, preservando la estabilidad macrofinanciera, robusteciendo el consumo doméstico y potenciando la innovación, China podría enfrentar este desafío sin abandonar los objetivos de su reforma económica: mayor espacio al mercado interno, mejorar la eficiencia de la inversión, incorporar las nuevas tecnologías al parque industrial, más énfasis en innovación, mayor equilibrio campo-ciudad y gradual construcción de una red de apoyo social que acompañe a los sectores más vulnerables.
Si las medidas de Trump siguen escalando, las autoridades chinas debieran desplegar planes económicos de emergencia, activando inversión en infraestructura rural (física y digital), reforzando las redes de apoyo social y los programas emblemáticos de Made in China 2025.

China debiera privilegiar un mayor acercamiento con la UE. Dado el interés de esta en una propuesta de reforma de la omc, China debería acompañar ese esfuerzo con mucha energía y América Latina, probablemente encabezada por la Alianza del Pacífico y mercosur, debería participar en ese debate, interactuando con la UE, con China, Japón, ASEAN y el propio Estados Unidos, en este importante desafío de gobernabilidad de la globalización del siglo XXI.

\section{Bibliografía}

Bloomberg (20I8). "After Defeating Cohn, Trump's Trade Warrior is on the Rise Again" Bloomberg, March $8^{\text {th }}$.

Bloomberg (2018a).“Foreign Companies Feeling Less Welcome in China, AmCham Says", January 3oth.Disponible en:https://www.bloomberg.com/news/ articles/20I8-OI-30/most-foreign-companies-feel-less-welcome-in-china-amcham-says.

Chi Fulin, ed. (2010). Change of China's Development Models at the Crossroads. CIRD, China Institute for Reform and Development, Beijing.
CNBC (20I8). "China says opening up of financial sector will need reciprocity”, May ${ }{ }^{\text {th }}$. Disponible en: https://www. cnbc.com/20r8/05/r9/china-says-opening-up-of-financial-sector-will-need-reciprocity.html

Department of Treasury (2018). "Report to the Congress. Macroeconomic and Foreign exchange Policies of Major Trading Partners of the U.S., April, Washington. Disponible en: https:// home.treasury.gov/sites/default/ files/20I8-04/20I8-04-I3-Spring-20I8FX-Report-FINAL.pdf 
European Chamber of Commerce (20I7). European Business in China. Position Paper.Disponible en:file:///G:/I.5.China20r8/European_Business_in_China_Short.pdf

Guo Keguang (2009). "Government Procurement: A Comparative Analysis of China and the United States" Dissertations, Theses and Capstone Projects. Paper 23. Kennesaw State University DigitalCommons@Kennesaw State University. Disponible en: http://citeseerx.ist.psu.edu/viewdoc/download?doi=Io.I.I.508.2336\&rep=repi\&type $=$ pdf

Lardy, N. (20I8). “China's Weapon in Trade are Formidable". Petersen Institute for International Economics, June $2 \mathrm{I}^{\text {th }}$.

Ming, L. (20I8). "US accusations it needs a reality check”. China Daily, 9 de Agosto.

McKinsey Global Institute (20I7). "Digital China: Powering the Economy to Global Competitiveness", pág. 3 . December.

Ostry, J.; Ghosh, A.; Chamon, M.yQureshi, M. (20I2). "Tools for Managing Financial-Stability Risks from Capital Inflows". Journal of International Economics, Vol. 88, No. 2, pp. 407-2I.
Lizhong, S. (2015). "El arte de la guerra de Sun Zi”. Casa editora Hua yi.

STM Report (20I8). STM Report: An overview of scientific and scholarly publishing. Disponible en:https://www.timeshighereducation.com/news/china-becomes-worlds-biggest-producer-scientific-research

USTR (20I8). “The President's Trade Policy Agenda", March It. Disponible en: https://ustr.gov/sites/default/files/ files/Press/Reports/20I8/AR/20I8\%20 Annual\%20Report\%20I.pdf

Willard, G. (1996). An Examination of China's Emerging Intellectual Property Regime: Historical Underpinnings, the Current System and Prospects for the Future. Indiana International \& Comparative Law Review, Vol. 6, No. 2, pp. 4II-437. Disponible en: https://mckinneylaw.iu.edu/iiclr/pdf/vol6p4II.pdf WTO (20I8). "China's Trade-Disruptive Economic Model”, presentación del representante de US en la OMC. WT/ GC/W/745, I6 de julio, 2018. 